\title{
Tiefere Prämien für Sie und Ihre Mitarbeiter
}

Kennen Sie die FMH Insurance Services Rahmenverträge für die obligatorische Unfallversicherung (UVG) und die kollektive Krankentaggeldversicherung (KTG)? FMH Services Mitglieder profitieren dabei von attraktiven Spezialkonditionen. Gerne erstellen wir Ihnen eine kostenlose und unverbindliche Vergleichsofferte zu Ihrer bestehenden Lösung und zeigen Ihnen Ihr Einsparpotential auf. Prüfen Sie unser Angebot, damit Sie und Ihre Mitarbeitenden Prämien sparen können.



$\square \quad$ Meine Mitarbeiter und ich wollen Prämien sparen. Bitte überprüfen Sie meine Personalversicherungen und senden Sie mir eine Vergleichsofferte zu. (Bitte Kopie der aktuellen Versicherungspolice beilegen.)

$\square \quad$ Ich wünsche eine persönliche Beratung. Bitte rufen Sie mich an.

Vorname / Name

Adresse

PLZ / Ort

Telefon Privat / Geschäft

Beste Zeit für einen Anruf

E-Mail-Adresse

Antworttalon: Bitte einsenden oder per Fax an 0319595010

\section{GMH INSURANCE}

Roth Gygax \& Partner AG $₫$ Koordinationsstelle Moosstrasse 2 a 3073 Gümligen

Telefon 0319595000 a Fax 0319595010 mail@fmhinsurance.ch nwww.fmhinsurance.ch 